\title{
Risk factors for intensive care admission in children with severe acute asthma in the Netherlands: a prospective multicentre study
}

\author{
Shelley A. Boeschoten ${ }^{1}$, Annemie L. Boehmer ${ }^{2,3}$, Peter J. Merkus ${ }^{4}$, \\ Joost van Rosmalen $\mathbb{1 0}^{5}$, Johan C. de Jongste6, Pieter L.A. Fraaij ${ }^{7,8}$, \\ Richard Molenkamp $\mathbb{1}^{8}$, Sabien G. Heisterkamp ${ }^{9}$, Job B. van Woensel ${ }^{9}$, \\ Berber Kapitein ${ }^{9}$, Eric G. Haarman ${ }^{10}$, Roelie M. Wösten-van Asperen ${ }^{11}$, \\ Martin C. Kneyber ${ }^{12}$, Joris Lemson ${ }^{13}$, Stan Hartman ${ }^{13}$, Dick A. van Waardenburg ${ }^{14}$, \\ Heleen E. Bunker-Wiersma ${ }^{15}$, Carole N. Brouwer ${ }^{15}$, Bart E. van Ewijk (1) ${ }^{16}$, \\ Anneke M. Landstra ${ }^{17}$, Mariel Verwaal ${ }^{2}$, Anja A. Vaessen-Verberne ${ }^{18}$, \\ Sanne Hammer ${ }^{18}$, Corinne M. Buysse ${ }^{1}$ and Matthijs de Hoog ${ }^{1}$
}

\section{ABSTRACT}

Rationale: Severe acute asthma (SAA) can be fatal, but is often preventable. We previously observed in a retrospective cohort study, a three-fold increase in SAA paediatric intensive care (PICU) admissions between 2003 and 2013 in the Netherlands, with a significant increase during those years of numbers of children without treatment of inhaled corticosteroids (ICS).

Objectives: To determine whether steroid-naïve children are at higher risk of PICU admission among those hospitalised for SAA. Furthermore, we included the secondary risk factors tobacco smoke exposure, allergic sensitisation, previous admissions and viral infections.

Methods: A prospective, nationwide multicentre study of children with SAA (2-18 years) admitted to all Dutch PICUs and four general wards between 2016 and 2018. Potential risk factors for PICU admission were assessed using logistic regression analyses.

Measurements and main results: $110 \mathrm{PICU}$ and 111 general ward patients were included. The proportion of steroid-naïve children did not differ significantly between PICU and ward patients. PICU children were significantly older and more exposed to tobacco smoke, with symptoms $>1$ week prior to admission. Viral susceptibility was not a significant risk factor for PICU admission.

Conclusions: Children with SAA admitted to a PICU were comparable to those admitted to a general ward with respect to ICS treatment prior to admission. Preventable risk factors for PICU admission were $>7$ days of symptoms without adjustment of therapy and exposure to tobacco smoke. Physicians who treat children with asthma must be aware of these risk factors.

@ERSpublications

Preventable risk factors for PICU admission among those with severe acute asthma are $>7$ days of symptoms without adjustment of therapy and environmental exposure to tobacco smoke, underlining the importance of smoking cessation of caregivers https://bit.ly/3ezPzxT

Cite this article as: Boeschoten SA, Boehmer AL, Merkus PJ, et al. Risk factors for intensive care admission in children with severe acute asthma in the Netherlands: a prospective multicentre study. ERJ Open Res 2020; 6: 00126-2020 [https://doi.org/10.1183/23120541.00126-2020].

This article has supplementary material available from openres.ersjournals.com

This study is registered at www.clinicaltrials.gov with identifier number NCT02936778.

Received: 9 March 2020 | Accepted after revision: 6 May 2020

Copyright $\odot$ ERS 2020. This article is open access and distributed under the terms of the Creative Commons Attribution Non-Commercial Licence 4.0. 


\section{Introduction}

Severe acute asthma (SAA; status asthmaticus) is a severe and potentially fatal asthma exacerbation that does not respond to standard treatment with bronchodilators and systemic corticosteroids [1]. Every child with asthma is at risk of SAA, even those with mild asthma $[2,3]$. Admission to a paediatric intensive care unit (PICU) occurs in $5-34 \%$ of all asthma hospitalisations [4-7]. Worldwide, the number of children requiring PICU admission increased markedly in the past decade, while the prevalence of asthma in children did not $[4,5,8,9]$. Previously, we showed a three-fold increase of children with SAA admitted to Dutch PICUs between 2003 and 2013, with a significant increase over the years in the proportion of steroid-naïve children [9].

New asthma guidelines [10] advise clinicians to look for key triggers that put patients at an increased risk of an exacerbation [11]. Multiple studies have focused on risk factors for PICU admission, with different outcomes. Those risk factors included inhaled corticosteroids (ICS) use [2, 7, 12], longer asthma duration [13], sex [7, 12], ethnicity [2], previous emergency department visits [13] or (PICU) hospitalisations [2, 14, 16-], sensitisation to (multiple) aeroallergens $[13,15]$ and exposure to environmental tobacco smoke (ETS) [14].

In contrast to the above studies, we included all these risk factors in this multicentre (including all Dutch PICUs) prospective study. Identifying risk factors offers the opportunity for early intervention to avoid PICU admission of children with SAA. Since daily ICS is the most effective treatment to reduce asthma symptoms and prevent exacerbations [1,17-20], we hypothesised that children without daily ICS are more prone to SAA requiring PICU admission. In addition, we looked into other risk factors such as ETS, viral infections, lower socioeconomic status (SES), sensitisation to (multiple) aeroallergens, and previous asthma-related healthcare visits.

\section{Methods}

We prospectively identified all children (aged 2-18 years) with SAA admitted to all seven Dutch academic PICUs or one of the paediatric wards of four participating general hospitals between 2016 and 2018. The four general hospitals were recruited based on geographical distribution over the Netherlands and needed to have a staff paediatric pulmonologist. Furthermore, these hospitals were good examples of general hospitals in the Netherlands, enhancing the external validity of the study. We included children aged $\geqslant 2$ years, since SAA treatment is the same for children across all age ranges in the Netherlands. For each group (PICU and general ward), patients were recruited until the pre-planned sample size of 110 patients per group had been achieved. SAA was defined as a doctor-diagnosed asthma exacerbation requiring systemic corticosteroids and hospital admission. According to Dutch national guidelines, all children receive the same initial treatment: oxygen, continuous inhalation with salbutamol plus ipratropium and systemic corticosteroids [21]. When the asthma score, as developed by QURESHI et al. [22], is still $\geqslant 10$ after three consecutive nebulisations with salbutamol plus ipratropium an intravenous magnesium sulphate bolus is administered. If continued nebulisation and i.v. magnesium sulphate lead to insufficient response, continuous infusion with salbutamol is started. When i.v. salbutamol is administered, children are transferred to a PICU, regardless of the dosage. Evidence indicates that this protocol is well followed in the Netherlands [9]. A child was classified as steroid-naïve when there was no maintenance treatment with ICS for $>7$ days before admission. The highest educational level of the parents and the postal code were used to determine SES. Ethnicity was defined as Caucasian or non-Caucasian. The severity of the

Affiliations: ${ }^{1}$ Intensive Care and Dept of Paediatric Surgery, Erasmus University Medical Center - Sophia Children's Hospital, Rotterdam, The Netherlands. ${ }^{2}$ Dept of Paediatrics, Maasstad Hospital, Rotterdam, The Netherlands. ${ }^{3}$ Dept of Paediatrics, Spaarne Hospital, Haarlem, The Netherlands. ${ }^{4}$ Division of Respiratory Medicine, Dept of Paediatrics, Radboudumc Amalia Children's Hospital, Nijmegen, The Netherlands. ${ }^{5}$ Dept of Biostatistics, Erasmus University Medical Center, Rotterdam, The Netherlands. ${ }^{6}$ Dept of Paediatric Pulmonology and Allergology, Erasmus University Medical Center - Sophia Children's Hospital, Rotterdam, The Netherlands. ${ }^{7}$ Dept of Paediatrics, Erasmus Medical Centre - Sophia Children's Hospital, Rotterdam, The Netherlands. ${ }^{8}$ ViroScience, Erasmus Medical Centre, Rotterdam, Netherlands. ${ }^{9}$ Paediatric Intensive Care Unit, Amsterdam University Medical Centers - Emma's Children's Hospital, Amsterdam, The Netherlands. ${ }^{10}$ Dept of Paediatrics, Amsterdam University Medical Centers - Emma's Children's Hospital, Amsterdam, The Netherlands. ${ }^{11}$ Paediatric Intensive Care Unit, Wilhelmina Children's Hospital/University Medical Center Utrecht, Utrecht, The Netherlands. ${ }^{12}$ Paediatric Intensive Care Unit, Beatrix Children's Hospital/University Medical Center Groningen, Groningen, The Netherlands. ${ }^{13}$ Paediatric Intensive Care Unit, University Medical Center Nijmegen, Nijmegen, The Netherlands. ${ }^{14}$ Paediatric Intensive Care Unit, Maastricht University Medical Center, Maastricht, The Netherlands. ${ }^{15}$ Paediatric Intensive Care Unit, Leiden University Medical Center, Leiden, The Netherlands. ${ }^{16}$ Dept of Paediatrics, Tergooi Hospital, Blaricum, The Netherlands. ${ }^{17}$ Dept of Paediatrics, Rijnstate Hospital, Arnhem, The Netherlands. ${ }^{18}$ Dept of Paediatrics, Amphia Hospital, Breda, The Netherlands.

Correspondence: Shelley A. Boeschoten, Dept of Paediatric Intensive Care Unit/Paediatric Surgery, Erasmus MC - Sophia, PO Box 2060, 3000CB Rotterdam, The Netherlands. E-mail: s.boeschotenderasmusmc.nl 
exacerbation at the time of admission was classified using the Asthma Score. Additional details on the definition of SES, ethnicity and the Dutch guidelines for PICU admission are provided in the supplementary material.

Adherence to ICS was expressed as the proportion of days covered (PDC) in the period preceding the index admission [23], according to the pharmacy records. Continuous and categorical measures of ICS adherence were used. For the categorical measures a PDC of $<80 \%$ (non-adherent) or a PDC $\geqslant 80 \%$ (adherent) were used. The cut-off values were chosen based on previous studies [24, 25].

We assessed a radioallergosorbent test for inhaled allergens in all children unless performed within the previous year. From every child, we acquired a nasal swab within $24 \mathrm{~h}$ after admission. The nasal swab was examined using real-time reverse transcriptase (RT)-PCR for the detection of viruses [26].

We determined urinary cotinine within $6 \mathrm{~h}$ after admission, as a proxy for ETS [27]. A value of $<10 \mathrm{ng} \cdot \mathrm{mL}^{-1}$ was interpreted as no recent ETS exposure; a value of $10-100 \mathrm{ng} \cdot \mathrm{mL}^{-1}$ as second-hand smoke exposure; and a value $>200 \mathrm{ng} \cdot \mathrm{mL}^{-1}$ as active smoking [28].

A blood sample for DNA analysis was only collected if blood was drawn for standard care measurements. DNA was isolated from $200 \mu \mathrm{L}$ of whole blood. Single nucleotide polymorphisms (SNPs) in the $A D R \beta 2$ at position 16 (rs1042713) and 27 (rs1042714), and SNPs in the CDHR3 (rs6967330) were characterised [29]. Further details on the methods for medication adherence and viral detection are provided in the supplementary material. Information about patient history, SES and environmental triggers was obtained from patients and caregivers using a web-based questionnaire, using LimeSurvey (version 2.06lts; www. limesurvey.org/).

\section{Analyses}

Data are presented as mean \pm SD or median (interquartile range). The Chi-squared test was used to compare categorical variables between both groups, and the Mann-Whitney test was used for continuous variables. Multivariate analysis was performed using multiple logistic regression analysis to evaluate the relationship between covariates and the probability of PICU admission.

Covariates were chosen based on the univariate analysis. Additional details on the sample size calculation and analyses are provided in the supplementary material. Given the potential difference in risk factors and

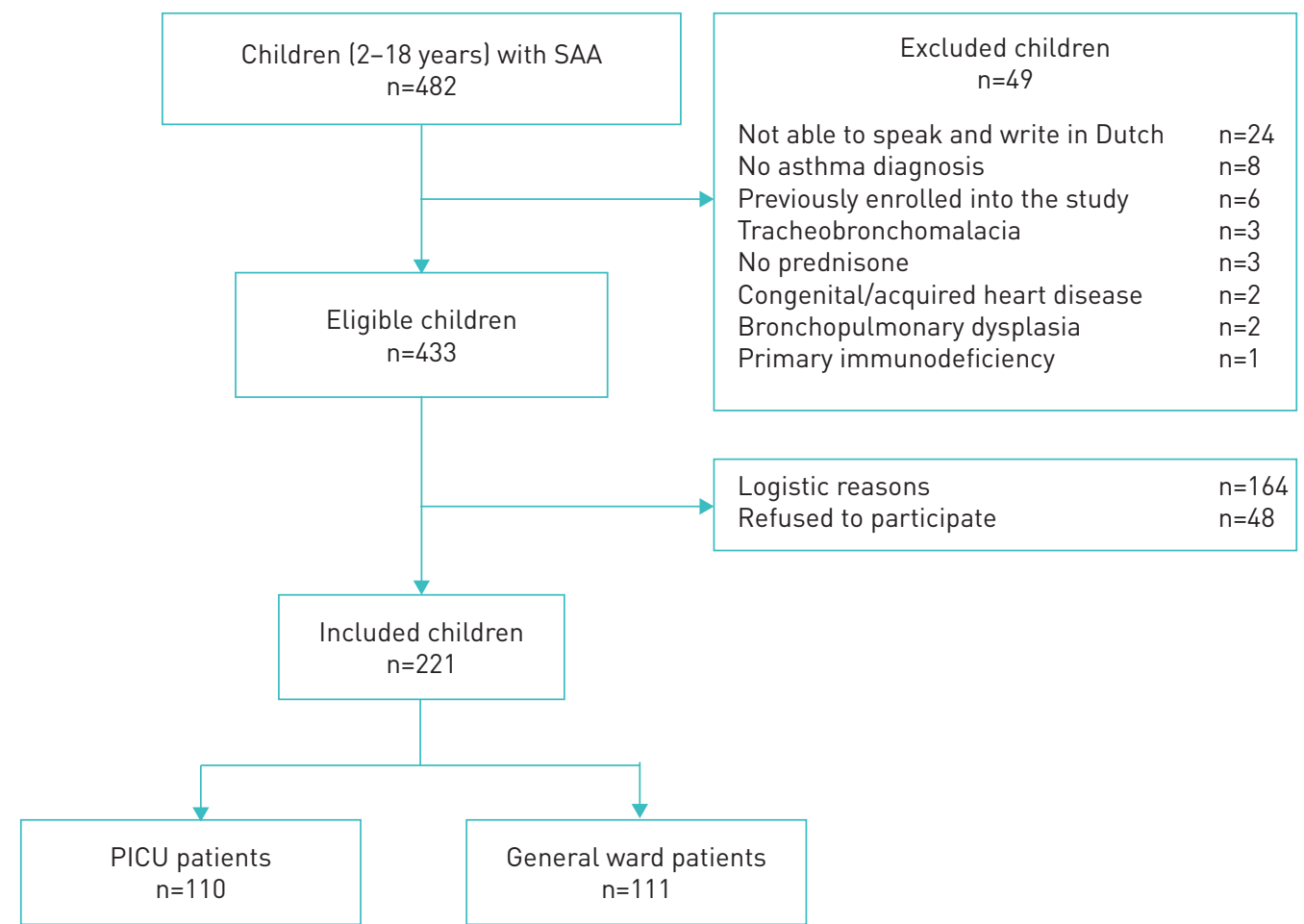

FIGURE 1 Flowchart of study enrolment. SAA: severe acute asthma; PICU: paediatric intensive care unit. 
diagnosis, a pre-planned subgroup analysis was performed for preschoolers (aged 2-4 years) versus school-aged children (aged 5-17 years). Statistical analyses were performed using SPSS (version 25; Chicago, IL, USA), and a two-sided significance level of 0.05 was used. Informed written consent was obtained before participation. The study was approved by the research ethics committee of the Erasmus Medical Center Rotterdam (MEC 2015-709) and adopted by the other hospitals.

\section{Results}

221 children were recruited into the study: 110 were admitted to the PICU and 111 to the general ward (figure 1). Table 1 shows their baseline characteristics.

Asthma was diagnosed before admission in $76 \%$ of the children admitted to the PICU and in $71 \%$ of the children admitted to the general ward. The proportion of steroid-naïve children, with or without a previous asthma diagnosis, did not differ significantly between PICU and general ward. Children admitted to the PICU were significantly older. Other significant factors associated with increased odds of PICU admission included being non-Caucasian, ICS adherence, asthma symptoms $>1$ week prior to admission and previous PICU admission (table 2). Two children died at the PICU of hypoxic ischaemic encephalopathy following out-of-hospital cardiac arrest, most likely due to patient delay and anaphylaxis.

The presence of human rhinovirus (HRV), or other viruses, was not a risk factor for PICU admission (table 3).

Table 4 shows presentation and in-hospital management. The asthma severity scores (Qureshi score) at admission were comparable between groups.

Multiple logistic regression analysis revealed that a PICU admission was significantly more likely in children who were older, had had symptoms $>1$ week prior to admission and were exposed to ETS (table 5).

Preschool children admitted to a PICU were less often treated by a paediatric pulmonologist prior to admission than children in the general ward group (supplementary table S1).

In school-aged children, significant factors associated with increased odds of PICU admission included being non-Caucasian, an older age, presence of symptoms $>1$ week prior to admission, and high urinary cotinine (all p-values $<0.017$; supplementary table S2). In multiple logistic regression analysis, an older age,

\begin{tabular}{|c|c|c|c|c|c|}
\hline \multirow[b]{2}{*}{ Subjects } & \multicolumn{2}{|c|}{ PICU } & \multicolumn{2}{|c|}{ Paediatric ward } & \multirow[t]{2}{*}{ p-value } \\
\hline & 110 & & 111 & & \\
\hline Age years & 110 & $8(5-12)$ & 111 & $5(3-7)$ & $<0.001$ \\
\hline Preschoolers (age 2-4 years) & 110 & $27(25)$ & 111 & $55(50)$ & $<0.001$ \\
\hline Male & 110 & $68(62)$ & 111 & $69(62)$ & 0.958 \\
\hline Caucasian & 110 & $60(55)$ & 111 & $79(71)$ & 0.011 \\
\hline Asthma diagnosis prior to admission & 110 & $84(76)$ & 111 & $79(71)$ & 0.380 \\
\hline \multicolumn{5}{|l|}{ Asthma treated by } & \multirow[t]{4}{*}{0.370} \\
\hline General practitioner & 82 & 29 (35) & 77 & $28(36)$ & \\
\hline Paediatrician & 82 & $31(38)$ & 77 & $22(29)$ & \\
\hline Paediatric pulmonologist & 82 & $22(27)$ & 77 & $27(35)$ & \\
\hline Steroid naïve & 110 & $56(51)$ & 111 & $67(60)$ & 0.157 \\
\hline \multicolumn{6}{|l|}{ Adherence to ICS" } \\
\hline PDC \% & 52 & $73 \pm 33$ & 43 & $62 \pm 30$ & 0.114 \\
\hline $\mathrm{PDC} \geqslant 80 \%$ & 52 & $30(58)$ & 43 & $16(37)$ & 0.047 \\
\hline Born $<37$ weeks' gestational age & 84 & $13(15)$ & 84 & $15(18)$ & 0.679 \\
\hline \multicolumn{5}{|l|}{ Highest parental education level } & \multirow[t]{4}{*}{0.390} \\
\hline Low & 82 & $3(4)$ & 84 & $1(1)$ & \\
\hline Middle & 82 & $35(43)$ & 84 & 31 (37) & \\
\hline High & 82 & $44(54)$ & 84 & $52(62)$ & \\
\hline SES scores ${ }^{+}$ & 110 & $-0.29 \pm 1.36$ & 111 & $-0.25 \pm 1.28$ & 0.824 \\
\hline \multicolumn{6}{|c|}{$\begin{array}{l}\text { Data are presented as } \mathrm{n} \text {, median (interquartile range), } \mathrm{n}(\%) \text { or mean } \pm \mathrm{SD} \text {, unless otherwise stated. Bold } \\
\text { type represents statistical significance. PICU: paediatric intensive care unit; ICS: inhaled corticosteroids; } \\
\text { PDC: proportion of days covered; SES: socioeconomic status. " } \text { : children with a diagnosis of asthma prior } \\
\text { to admission. ๆ: of the children with prescribed ICS. }{ }^{+}: \text {the postal code was used to quantify the } \\
\text { neighbourhood SES, with a mean of zero. A lower (negative) score is associated with a lower SES. }\end{array}$} \\
\hline
\end{tabular}




\begin{tabular}{|c|c|c|c|c|c|}
\hline \multirow{3}{*}{ Subjects } & \multicolumn{2}{|c|}{ PICU } & \multicolumn{2}{|c|}{ Paediatric ward } & \multirow[t]{2}{*}{ p-value } \\
\hline & 110 & & 111 & & \\
\hline & & & & & 0.076 \\
\hline Step 1 & 110 & $31(28)$ & 111 & $42(38)$ & \\
\hline Step 2 & 110 & $12(11)$ & 111 & $10(9)$ & \\
\hline Step 3 & 110 & $18(16)$ & 111 & $24(22)$ & \\
\hline Step 4 & 110 & $24(22)$ & 111 & $10(9)$ & \\
\hline Step 5 & 110 & & 111 & & \\
\hline No medication & 110 & $25(23)$ & 111 & $25(23)$ & \\
\hline Symptoms $>1$ week prior to admission & 108 & $60(55)$ & 109 & $25(23)$ & $<0.001$ \\
\hline \multicolumn{6}{|l|}{ Prior hospital admissions } \\
\hline Non-PICU & 106 & $64(60)$ & 97 & $69(71)$ & 0.107 \\
\hline Ever to PICU & 110 & $15(14)$ & 111 & $6(5)$ & 0.037 \\
\hline Admission in previous year & 108 & $32(30)$ & 111 & $30(27)$ & 0.669 \\
\hline Emergency department visits previous year & & & & & 0.022 \\
\hline None & 84 & $38(45)$ & 84 & $21(25)$ & \\
\hline $1-3$ & 84 & $41(49)$ & 84 & 57 (68) & \\
\hline$>3$ & 84 & $5(6)$ & 84 & $6(7)$ & \\
\hline Prednisolone course in the previous year & 84 & $56(67)$ & 84 & $71(85)$ & 0.007 \\
\hline
\end{tabular}

symptoms $>1$ week prior to admission and elevated cotinine remained statistically significant predictors of PICU admission (supplementary table S3).

\section{Discussion}

In this nationwide multicentre prospective study, we found no significant difference in the proportion of steroid-naïve children with SAA admitted to a PICU or a general ward. In general, PICU children were older, more exposed to tobacco smoke and had a longer duration of asthma symptoms before admission.

Daily ICS or ICS as rescue medication with a short-acting $\beta$-agonist (SABA) protects against asthma exacerbations compared to SABA alone [17, 30], but uncontrolled asthma is not rare [31], even in children

\begin{tabular}{|c|c|c|c|c|c|}
\hline \multirow[b]{2}{*}{ Subjects } & \multicolumn{2}{|c|}{ PICU } & \multicolumn{2}{|c|}{ Paediatric ward } & \multirow[t]{2}{*}{ p-value } \\
\hline & 110 & & 111 & & \\
\hline Allergic sensitisation" & 103 & 79 (77) & 110 & $71(65)$ & 0.052 \\
\hline Multiple sensitisation" & 102 & $24(24)$ & 110 & $15(14)$ & 0.063 \\
\hline Food allergies & 56 & 22 (39) & 53 & $7(13)$ & NA \\
\hline \multicolumn{6}{|l|}{ Respiratory viral infections } \\
\hline PCR positive for $\geqslant 1$ virus & 102 & $56(55)$ & 104 & 65 (63) & 0.268 \\
\hline PCR positive for $\geqslant 2$ viruses & 102 & $7(7)$ & 104 & $14(13)$ & 0.191 \\
\hline Symptoms and PCR positive & 98 & $44(45)$ & 103 & $53(52)$ & 0.352 \\
\hline PCR positive for rhinovirus & 102 & $42(41)$ & 104 & $56(54)$ & 0.069 \\
\hline Rhinovirus A & 22 & $10(46)$ & 33 & $17(52)$ & 0.448 \\
\hline Rhinovirus B & 22 & $1(5)$ & 33 & 0 & \\
\hline Rhinovirus C & 22 & $11(50)$ & 33 & $16(49)$ & \\
\hline Parental self-reported smoking & 103 & $28(27)$ & 108 & $26(24)$ & 0.812 \\
\hline Urinary cotinine & & & & & 0.150 \\
\hline Nonsmoker $<10 \mathrm{ng} \cdot \mathrm{mL}^{-1}$ & 96 & $74(77)$ & 89 & 77 (87) & \\
\hline Passive smoker $>10 \mathrm{ng} \cdot \mathrm{mL}^{-1}$ & 96 & $20(21)$ & 89 & $12(13)$ & \\
\hline Active smoker $>200 \mathrm{ng} \cdot \mathrm{mL}^{-1}$ & 96 & $2(2)$ & 89 & & \\
\hline Siblings $>2$ & 84 & $25(30)$ & 84 & $26(31)$ & 0.867 \\
\hline
\end{tabular}

Data are presented as $\mathrm{n}$ or $\mathrm{n}(\%)$, unless otherwise stated. PICU: paediatric intensive care unit; NA: not available. \# : positive radioallergosorbent test (RAST) $=\lg \mathrm{E}>0.7 \mathrm{kU} \cdot \mathrm{L}^{-1}$ for at least one of the allergens; ๆ: positive RAST for at least one pet, pollen and house dust mite. 


\section{TABLE 4 Presentation and in-hospital management}

\begin{tabular}{|c|c|c|c|c|c|}
\hline & \multicolumn{2}{|c|}{ PICU } & \multicolumn{2}{|c|}{ Paediatric ward } & \multirow[t]{2}{*}{ p-value } \\
\hline Subjects & 110 & & 111 & & \\
\hline $\mathrm{pH}^{\#}$ & 102 & $7.34 \pm 0.1$ & Not done & & \\
\hline$P_{\mathrm{CO}_{2}} \mathrm{kPa}^{\#}$ & 102 & $5.5 \pm 1.8$ & Not done & & \\
\hline Asthma severity score (Qureshi) & & & & & 0.439 \\
\hline Mild & 105 & $6(6)$ & 106 & $9(8)$ & \\
\hline Moderate & 105 & $50(48)$ & 106 & $56(53)$ & \\
\hline Severe & 105 & $49(47)$ & 106 & $41(39)$ & \\
\hline \multicolumn{6}{|l|}{ Acute asthma treatment } \\
\hline Inhaled short-acting $\beta$-agonist & 110 & 108 (98) & 111 & $111(100)$ & 0.154 \\
\hline Systemic corticosteroids & 110 & 109 (99) & 111 & 110 (99) & 0.995 \\
\hline Antibiotics & 110 & $45(41)$ & 110 & $18(16)$ & $<0.001$ \\
\hline Intravenous magnesium & 110 & $108(98)$ & 111 & $16(14)$ & $<0.001$ \\
\hline Intravenous salbutamol & 110 & 109 (99) & 111 & 0 & $<0.001$ \\
\hline Ketamine & 110 & $12(11)$ & 111 & 0 & $<0.001$ \\
\hline Theophylline & 110 & $7(6)$ & 111 & 0 & $<0.001$ \\
\hline Maximal respiratory support & & & & & $<0.001$ \\
\hline None & 110 & $1(1)$ & 111 & $26(23)$ & \\
\hline Nasal cannula & 110 & $15(14)$ & 111 & $71(64)$ & \\
\hline Non-rebreathing mask & 110 & $34(31)$ & 111 & $14(13)$ & \\
\hline High-flow nasal cannula & 110 & $46(42)$ & 111 & & \\
\hline Noninvasive ventilation & 110 & $1(1)$ & 111 & & \\
\hline Invasive mechanical ventilation & 110 & $13(12)$ & 111 & & \\
\hline \multicolumn{6}{|l|}{ Disposition } \\
\hline Sent home & 110 & 108 (98) & 111 & $111(100)$ & \\
\hline Died in the hospital & 110 & $2(2)$ & 111 & 0 & \\
\hline Hospital length of stay days & 107 & $6.3 \pm 2.3$ & 111 & $3.2 \pm 1.2$ & $<0.001$ \\
\hline $\begin{array}{l}\text { Data are presented as } n \text {, mean } \\
\text { significance. PICU: paediatric int } \\
\text { blood sample. }\end{array}$ & 1 & $\begin{array}{l}\text { ess oth } \\
\mathrm{CO}_{2}: \text { cart }\end{array}$ & xide ten & $\begin{array}{l}\text { pe repres } \\
\text { determin }\end{array}$ & $\begin{array}{l}\text { atistical } \\
\text { capillary }\end{array}$ \\
\hline
\end{tabular}

with daily ICS, and was a risk factor for PICU admission in some studies [2, 7]. This might be due to the fact that children using ICS had persistent and more severe asthma and consequently a higher risk for SAA and PICU admission. This theory is supported by the fact that children admitted to the PICU had a significantly higher ICS dose prior to admission. In our study, risk factors for PICU admission seem to be driven by host (age, ethnic background and patient delay) and environmental (exposure to ETS) characteristics, rather than ICS use only. Targeted strategies aimed at the prevention of severe asthma exacerbations, even despite treatment with daily ICS, are needed. Strategies such as enhancing awareness in the general population of symptoms of asthma or uncontrolled asthma may empower the general public to seek medical help earlier than some parents in this study. The risk of children having dangerous asthma exacerbations as a result of cigarette smoke exposure is yet another clear effect of cigarette smoke exposure that legislatures need to take into account in smoke-free policies.

TABLE 5 Multiple logistic regression analysis of risk factors for paediatric intensive care unit (PICU) admission

\begin{tabular}{|c|c|c|}
\hline & OR $(95 \% \mathrm{CI})$ & p-value \\
\hline Steroid naïve & $1.144(0.575-2.276)$ & 0.702 \\
\hline Age in years $\#$ & $1.263(1.141-1.399)$ & $<0.001$ \\
\hline Female & $1.407(0.722-2.745)$ & 0.316 \\
\hline Caucasian & $0.532(0.273-1.039)$ & 0.064 \\
\hline Respiratory viral infection & $1.207(0.601-2.424)$ & 0.597 \\
\hline Symptoms $>1$ week prior to admission & $4.252(2.130-8.489)$ & $<0.001$ \\
\hline Previous PICU admissions & $2.785(0.873-8.879)$ & 0.083 \\
\hline Positive urinary cotinine $>10 \mathrm{ng} \cdot \mathrm{mL}^{-1}$ & $3.733(1.442-9.659)$ & 0.007 \\
\hline
\end{tabular}


The most important risk factor for PICU admission was having symptoms for $>1$ week prior to admission. These children were significantly older (median age 8 years versus 6 years). Only $30 \%$ of the children with symptoms for $>1$ week prior to admission received oral corticosteroids (OCS) before arrival at the emergency department. Patient and doctor delay contributed to a longer duration of symptoms followed by a more severe attack. Early treatment with OCS in these children could have possibly prevented hospitalisation or PICU admission. Hospital admission produces a high level of stress on the child and caregivers, especially at the PICU. Furthermore, bed availability and the high medical costs emphasise the need for a more vigilant approach if symptoms persist to prevent PICU admission.

The age difference between the PICU and general ward group could be due to the fact that these groups represent different disease categories. STEIN and Martinez [32] have shown that asthma phenotypes are markedly heterogeneous in the first 6 years of life. In fact, some of these phenotypes are transient and seem to behave idiosyncratically.

In agreement with previous studies, exposure to ETS was significantly associated with a higher frequency of PICU admission [2] or emergency department management failure [33]. In the PICU population, children with ETS-associated SAA deteriorated and recovered more slowly than non-ETS-exposed children [34]. Additional to previous studies we used urinary cotinine to quantify and identify ETS as an objective risk factor for PICU admission among children hospitalised for SAA. Caregivers should be made aware that ETS confers a four-fold increased risk for PICU admission in case of SAA, and offered appropriate support to stop smoking. Preferably, any financial obstacles should be reimbursed.

Our data corroborate previous studies reporting that the majority of children requiring hospital admission were allergically sensitised and had at least one viral respiratory infection identified, mostly due to rhinovirus [2, 13, 15, 35-38]. In our study, HRV-C was not a risk factor for PICU admission among children hospitalised for asthma. Although we found a high HRV-C prevalence, in itself it may be a risk factor for hospitalisation, but not differentiate in terms of severity beyond that point.

Children with SAA admitted to Dutch PICUs have a relatively short PICU stay compared with the general PICU population. According to the Dutch paediatric guideline for SAA [21], continuous i.v. administration of salbutamol requires immediate transfer to a PICU, regardless of the dosage. Hence, children in our study might have had less severe illness than asthmatic children in other PICU studies, as suggested by the low numbers of children requiring invasive mechanical ventilation and low mortality [2].

Of the children admitted to the PICU, 24\% were first presentations. Hence in these children a PICU admission could not easily have been prevented except for education of the general public on asthma symptoms.

In addition, we looked at the effect of polymorphisms of the $A D R \beta 2$ and $C D H R 3$ asthma risk alleles, since the $A D R \beta 2$ gene might reduce bronchodilator responsiveness in asthmatic children [39], and the CDHR3 asthma risk allele is associated with more severe HRV-C-induced asthma attacks [40]. In our study, genotyping of the $A D R \beta 2$ at position 16 (rs1042713) and 27 (rs1042714), and the CDHR3 asthma risk allele (rs6967330) showed no significant differences between PICU and general ward (data not shown). However, our study was not powered to detect a difference.

\section{Limitations/strengths}

Strengths of the present study are a high inclusion rate of $75 \%$ of children admitted to all Dutch PICUs, with standardised criteria for PICU admission. We investigated multiple potential risk factors, including objective measures such as cotinine in the urine for exposure to ETS, RT-PCR for viral infections, and use of asthma medication based on pharmacy records. There are some limitations as well. First, asthma was defined as diagnosed by a paediatrician prior to or during the exacerbation. The diagnosis was reviewed by a paediatric pulmonologist at the follow-up visits. We are well aware that asthma may be undistinguishable from acute viral wheeze in children aged $<6$ years; however, this will not affect treatment decisions in the setting of SAA. All children were seen by a paediatric pulmonologist during follow-up and $90 \%$ still used asthma medication after 3-9 months (the remaining 10\% were lost to follow-up), which supports that the initial asthma diagnosis was correct. Second, data regarding lung function at time of presentation to the emergency department are lacking. Only 20 (18\%) children in the PICU group had performed lung function testing recently: 13 children had airflow obstruction, nine children had forced expiratory volume in $1 \mathrm{~s}\left(\mathrm{FEV}_{1}\right)<80 \%$. In the general ward group, $10(9 \%)$ children performed a lung function test prior to admission: three children had airflow obstruction, with a $\mathrm{FEV}_{1}<80 \%$ in one child. Third, we used the PDC in the period preceding the index admission as a proxy for ICS treatment. Although the PDC is an objective measurement, this is not equivalent to the actual use of medication or good inhalation technique. Lastly, $30 \%$ of DNA analysis is missing in the general ward group because blood samples were only collected if blood was drawn for routine care measurements. 


\section{Conclusion}

We found no significant differences in the proportion of steroid-naïve children between children with SAA admitted to the PICU versus those admitted to a general ward. Prolonged duration of symptoms prior to admission and environmental tobacco smoke exposure were clinically relevant strong risk factors for PICU admission. These are preventable triggers and our data clearly support the call for smoking cessation by caretakers of children. We recommend a rapid and vigilant approach for children with prolonged asthma symptoms as they are at high risk for PICU admission for SAA.

Acknowledgements: The authors thank the research consortium SKIC members (Dutch Collaborative PICU Research Network).

Conflict of interest: S.A. Boeschoten has nothing to disclose. A.L. Boehmer has nothing to disclose. P.J. Merkus reports grants from Chiesi Netherlands BV and Novartis Netherlands BV during the conduct of the study. J. van Rosmalen has nothing to disclose. J.C. de Jongste has nothing to disclose. P.L.A. Fraaij reports grants from EU FP7 PREPARE (\#602525). R. Molenkamp has nothing to disclose. S.G. Heisterkamp has nothing to disclose. J.B. van Woensel has nothing to disclose. B. Kapitein has nothing to disclose. E.G. Haarman has nothing to disclose. R.M. Wösten-van Asperen has nothing to disclose. M.C. Kneyber has nothing to disclose. J. Lemson has nothing to disclose. S. Hartman has nothing to disclose. D.A. van Waardenburg has nothing to disclose. H.E. Bunker-Wiersma has nothing to disclose. C.M. Brouwer has nothing to disclose. B.E. van Ewijk has nothing to disclose. A.M. Landstra has nothing to disclose. M. Verwaal has nothing to disclose. A.A. Vaessen-Verberne has nothing to disclose. S. Hammer has nothing to disclose C.M. Buysse reports grants from the AMMODO and SAB foundations outside the submitted work. M. de Hoog reports grants from the AMMODO and SAB foundations outside the submitted work.

Support statement: This study was financially supported by the Dutch Foundation for Asthma Prevention (Stichting Astma Bestrijding), Ammodo (Institute of Art and Science), unrestricted grants of Chiesi Pharmaceuticals BV Netherlands and Novartis Pharma, B.V. The Netherlands. Funding information for this article has been deposited with the Crossref Funder Registry.

\section{References}

1 Global Initiative for Asthma (GINA). Global Strategy for Asthma Management and Prevention. 2019. Available from: http://ginasthma.org/gina-reports/

2 Grunwell JR, Travers C, Fitzpatrick AM. Inflammatory and comorbid features of children admitted to a PICU for status asthmaticus. Paediatr Crit Care Med 2018; 19: e585-e594.

3 Sheikh S, Khan N, Ryan-Wenger NA, et al. Demographics, clinical course, and outcomes of children with status asthmaticus treated in a paediatric intensive care unit: 8-year review. J Asthma 2013; 50: 364-369.

4 Tse SM, Samson C. Time to asthma-related readmission in children admitted to the ICU for asthma. Paediatr Crit Care Med 2017; 18: 1099-1105.

5 Hartman ME, Linde-Zwirble WT, Angus DC, et al. Trends in admissions for paediatric status asthmaticus in New Jersey over a 15-year period. Paediatrics 2010; 126: e904-e911.

6 Bratton SL, Odetola FO, McCollegan J, et al. Regional variation in ICU care for paediatric patients with asthma. J Paediatr 2005; 147: 355-361.

7 Hasegawa K, Ahn J, Brown MA, et al. Underuse of guideline-recommended long-term asthma management in children hospitalized to the intensive care unit: a multicenter observational study. Ann Allergy Asthma Immunol 2015; 115: 10-16.

8 Chiang BL, Hsieh CT, Wang LC, et al. Clinical course and outcome of children with status asthmaticus treated in a paediatric intensive care unit: a 15-year review. J Microbiol Immunol Infect 2009; 42: 488-493.

9 Boeschoten SA, Buysse CMP, Merkus P, et al. Children with severe acute asthma admitted to Dutch PICUs: a changing landscape. Paediatr Pulmonol 2018; 53: 857-865.

10 British Thoracic Society, Scottish Intercollegiate Guidelines Network. SIGN 158. British Guideline on the Management of Asthma 2019. www.brit-thoracic.org.uk/quality-improvement/guidelines/asthma/

11 Mahase E. Asthma: assess all patients for future attack risk and tailor care accordingly, new guideline advises. $B M J$ 2019; 366: 14846

12 Lyell PJ, Villanueva E, Burton D, et al. Risk factors for intensive care in children with acute asthma. Respirology 2005; 10: 436-441.

13 Belessis Y, Dixon S, Thomsen A, et al. Risk factors for an intensive care unit admission in children with asthma. Paediatr Pulmonol 2004; 37: 201-209.

14 van den Bosch GE, Merkus PJ, Buysse CM, et al. Risk factors for paediatric intensive care admission in children with acute asthma. Respir Care 2012; 57: 1391-1397.

15 McDowell KM, Kercsmar CM, Huang B, et al. Medical and social determinants of health associated with intensive care admission for asthma in children. Ann Am Thorac Soc 2016; 13: 1081-1088.

16 Elizur A, Bacharier LB, Strunk RC. Paediatric asthma admissions: chronic severity and acute exacerbations. J Asthma 2007; 44: 285-289.

17 Martinez FD, Chinchilli VM, Morgan WJ, et al. Use of beclomethasone dipropionate as rescue treatment for children with mild persistent asthma (TREXA): a randomised, double-blind, placebo-controlled trial. Lancet 2011; 377: 650-657.

18 Guilbert TW, Morgan WJ, Zeiger RS, et al. Long-term inhaled corticosteroids in preschool children at high risk for asthma. N Engl J Med 2006; 354: 1985-1997.

19 Sorkness CA, Lemanske RF Jr, Mauger DT, et al. Long-term comparison of 3 controller regimens for mild-moderate persistent childhood asthma: the Paediatric Asthma Controller Trial. J Allergy Clin Immunol 2007; 119: 64-72.

20 Verberne AA, Frost C, Roorda RJ, et al. One year treatment with salmeterol compared with beclomethasone in children with asthma. The Dutch Paediatric Asthma Study Group. Am J Respir Crit Care Med 1997; 156: 688-695. 
21 Nederlandse Vereniging voor Kindergeneeskunde. Dutch Society of Pediatrics - Guideline Status Asthmaticus in Children. Available from: www.nvk.nl/Portals/0/richtlijnen/acuut\%20astma/Methodenacuutastma.pdf 2012

22 Qureshi F, Pestian J, Davis P, et al. Effect of nebulized ipratropium on the hospitalization rates of children with asthma. N Engl J Med 1998; 339: 1030-1035.

23 Peterson AM, Nau DP, Cramer JA, et al. A checklist for medication compliance and persistence studies using retrospective databases. Value Health 2007; 10: 3-12.

24 Camargo CA Jr, Ramachandran S, Ryskina KL, et al. Association between common asthma therapies and recurrent asthma exacerbations in children enrolled in a state Medicaid plan. Am J Health Syst Pharm 2007; 64: 1054-1061.

25 Engelkes M, Janssens HM, de Jongste JC, et al. Medication adherence and the risk of severe asthma exacerbations: a systematic review. Eur Respir J 2015; 45: 396-407.

26 Moesker FM, van Kampen JJ, van der Eijk AA, et al. Human bocavirus infection as a cause of severe acute respiratory tract infection in children. Clin Microbiol Infect 2015; 21: 964.e1-964.e8.

27 Bramer SL, Kallungal BA. Clinical considerations in study designs that use cotinine as a biomarker. Biomarkers 2003; 8: 187-203.

28 Florescu A, Ferrence R, Einarson T, et al. Methods for quantification of exposure to cigarette smoking and environmental tobacco smoke: focus on developmental toxicology. Ther Drug Monit 2009; 31: 14-30.

29 Erasmus MC University Medical Center Rotterdam. GSA-MD, version 2 array. www.glimdna.org/global-screeningarray.html 2016

30 O'Byrne PM, FitzGerald JM, Bateman ED, et al. Inhaled combined budesonide-formoterol as needed in mild asthma. N Engl J Med 2018; 378: 1865-1876.

31 Lemanske RF Jr, Mauger DT, Sorkness CA, et al. Step-up therapy for children with uncontrolled asthma receiving inhaled corticosteroids. N Engl J Med 2010; 362: 975-985.

32 Stein RT, Martinez FD. Asthma phenotypes in childhood: lessons from an epidemiological approach. Paediatr Respir Rev 2004; 5: 155-161.

33 Ducharme FM, Zemak R, Chauhan BF, et al. Factors associated with failure of emergency department management in children with acute moderate or severe asthma: a prospective, multicentre, cohort study. Lancet Respir Med 2016; 4: 990-998.

34 Samir S, Colin Y, Thomas S. Impact of environmental tobacco smoke on children admitted with status asthmaticus in the pediatric intensive care unit. Pediatr Pulmonol 2011; 46: 224-229.

35 Johnston SL, Pattemore PK, Sanderson G, et al. Community study of role of viral infections in exacerbations of asthma in 9-11 year old children. BMJ 1995; 310: 1225-1229.

36 Heymann PW, Platts-Mills TA, Johnston SL. Role of viral infections, atopy and antiviral immunity in the etiology of wheezing exacerbations among children and young adults. Paediatr Infect Dis J 2005; 24: S217-S222.

37 Merckx J, Ducharme FM, Martineau C, et al. Respiratory viruses and treatment failure in children with asthma exacerbation. Pediatrics 2018; 142: e20174105.

38 Kantor DB, Stenquist N, McDonald MC, et al. Rhinovirus and serum IgE are associated with acute asthma exacerbation severity in children. J Allergy Clin Immunol 2016; 138: 1467-1471.

39 Finkelstein Y, Bournissen FG, Hutson JR, et al. Polymorphism of the ADRB2 gene and response to inhaled beta-agonists in children with asthma: a meta-analysis. J Asthma 2009; 46: 900-905.

40 Bønnelykke K, Coleman AT, Evans MD, et al. Cadherin-related family member 3 genetics and rhinovirus C respiratory illnesses. Am J Respir Crit Care Med 2018; 197: 589-594. 